\title{
Safety of antiarrhythmic drugs in children
}

\begin{abstract}
Amiodarone
Amiodarone has been used as an antiarrhythmic agent for many years ${ }^{1}$ and is known to be effective, but with potentially serious long-term adverse effects. ${ }^{12}$ It has been used in children successfully for years ${ }^{3-7}$ both acutely, intravenously, ${ }^{4}$ and chronically, orally. ${ }^{3-7}$ Though side effects have, as expected, been described in children, ${ }^{4-7}$ amiodarone has been described as "close to being the ideal antiarrhythmic agent in children's arrhythmias". ${ }^{3}$ Others, however, have been more cautious in recommending it as an effective antiarrhythmic agent. ${ }^{67}$

Till et al (page 84) report two possible adverse effects of amiodarone in a 10 day old infant with a history of fetal arrhythmia and hydrops. ${ }^{8}$ Immediately after the start of an intravenous infusion of amiodarone the infant collapsed with wide complex bradycardia and required resuscitation. This is a recognised complication of intravenous amiodarone therapy. ${ }^{9}$ The infant, who was shown to have Wolff-Parkinson-White syndrome, recovered and subsequently developed atrial flutter with 1:1 atrioventricular conduction over the accessory pathway. This effect is predictable because amiodarone slows conduction in the atrioventricular node, ${ }^{1}$ and may also slow conduction in an accessory pathway. If atrioventricular nodal conduction is slowed more than accessory pathway conduction, preferential pathway conduction will occur, particularly as amiodarone also reduces atrial excitability and increases atrial conduction time, leading to slowing in the flutter rate. All of these factors may favour 1:1 conduction during atrial flutter.
\end{abstract}

\section{Flecainide}

Elsewhere Till and Herxheimer report ${ }^{10}$ another serious adverse effect of an antiarrhythmic agent: the death of a five year old child with recurrent supraventricular tachycardia, who was taking flecainide, was attributed to an arrhythmia - by implication caused by flecainide.

The use of flecainide in children has been studied extensively ${ }^{11} 12$ and has been considered to be both effective and safe. It has been known for several years that flecainide can provoke serious ventricular arrhythmias in adults. ${ }^{1314}$ In children it has been reported to cause incessant supraventricular tachycardia, ${ }^{11} 1516$ cardiac arrest, or sudden death ${ }^{15} 16$ and non-sustained ventricular tachycardia. ${ }^{16}$ The incidence of arrhythmogenesis is lower in children than in adults, however. ${ }^{17}$

The preliminary and subsequent reports of the Cardiac Arrhythmia Suppression Trial have caused much concern about the use of antiarrhythmic drugs in general and flecainide and encainide in particular. ${ }^{18}$ However, this trial related to a very specific group of patients (postinfarction patients with asymptomatic ventricular ectopy) not commonly treated with antiarrhythmic drugs in the United Kingdom, and it has been thought that the results cannot necessarily be extrapolated to other groups of patients, ${ }^{19}$ including children. It has been widely assumed that potentially serious adverse effects are less frequent in patients with normal cardiac function. ${ }^{1620}$

The arrhythmogenic effects of flecainide (and encainide) in children have been reviewed recently, and were reported in $7.5 \%$ of 472 young patients treated with flecainide..$^{15}$ Interestingly, arrhythmogenesis was equally common in those with structural heart disease and those without. This review has generated debate and controversy $^{1621}$ and further review of the use of flecainide in 704 children (including the 472 considered above) ${ }^{16}$ suggests that flecainide is effective and probably safe in children with supraventricular tachycardia and structurally normal hearts. This difference in opinion based on reviews of similar and overlapping data highlights some of the difficulties in prescribing for paediatric arrhythmias.

\section{Other agents}

Other newer antiarrhythmic drugs have been used in children. Propafenone has been shown to be effective, but arrhythmogenesis occurred in two of 58 children and one child died suddenly. ${ }^{22}$ Similarly, sotalol has been shown to be effective, but one of 66 patients required a pacemaker for bradycardia..$^{23}$

Experience in the United Kingdom is more limited. The Committee on Safety of Medicines (CSM) database contains only 13 reports of suspected adverse reactions to antiarrhythmic agents in children. ${ }^{24}$ Nine of these relate to amiodarone and only one was potentially serious; three (including that discussed above) relate to flecainide. ${ }^{24}$ One was fatal ${ }^{10}$ and one potentially serious (incessant tachycardia).

\section{Guidance}

There is relatively little guidance available in standard paediatric (or indeed adult cardiology) texts $\mathrm{s}^{25}$ on the management of arrhythmias in children. Vagal manoeuvres are recommended in infants, then digoxin, then cardioversion. ${ }^{25}$ Other antiarrhythmic drugs, including propranolol, flecainide, and disopyramide (but no longer verapamil) are suggested as later options. ${ }^{25}$ Verapamil is recommended for older children, with lignocaine, mexiletine, and disopyramide as second line drugs in older children. ${ }^{26}$ The British National Formulary contains little advice on the treatment of arrhythmias in children. It states that verapamil "should not be used in children with arrhythmias without specialist advice". ${ }^{27}$ The Data Sheet Compendium gives no advice on either indications for or specific doses of antiarrhythmic drugs in children except for verapamil. ${ }^{28}$ Verapamil has, however, been reported to be associated with cardiovascular collapse and death, particularly in infants. ${ }^{29-31}$

Thus management of arrhythmias is complex and difficult both in adults and in children. Information about efficacy and safety in children in particular is incomplete. Readily accessible information, particularly that likely to be available in an emergency, is either lacking or conflicting. The two case reports discussed emphasise some of 
the potentially serious and fatal problems that can occur even in centres with experience of managing these problems. Management of children with arrhythmias should therefore be closely supervised by paediatric cardiologists, and preferably electrophysiologists (with paediatric experience) with access to electrocardiographic monitoring, monitoring of drug concentrations, paediatric intensive care facilities, and the newer non-pharmacological techniques of arrhythmia management.

Department of Cardiology, Freeman Hospital,

JANET M MCCOMB Newcastle upon Tyne NE7 7DN

1 Mason JW. Amiodarone. N Engl f Med 1987;316:455-66.

2 Harris L, McKenna WJ, Rowland E, Holt DW, Storey GCA, Krikler DM. Side effects of long-term amiodarone therapy. Circulation 1983; 67:45-51.

3 Coumel P, Lucet $\mathrm{V}$, Ngoc DD. The use of amiodarone in children. PACE 1983;6:930-9.

4 Bucknall CA, Keeton BR, Curry PVL, Tynan MJ, Sutherland GR, Holt $\mathrm{DW}$. Intravenous and oral amiodarone for arrhythmias in children. $B$ Heart f 1986;56:278-84.

5 Coumel P, Fidelle J. Amiodarone in the treatment of cardiac arrhythmias in children: one hundred thirtyfive cases. Am Heart $\mathcal{F} 1980 ; 100: 1063-9$.

6 Guccione P, Paul T, Garson A. Long term follow up of amiodarone therapy in the young: continued efficacy, unimpaired growth, moderate side effects. F Am Coll Cardiol 1990;15:1118-24.

7 Garson A, Gillette P, McVey P, Hesslein PS, Porter CJ, Angell LK, Kaldis LC, Hittner HM. Amiodarone treatment of critical arrhythmias in children and young adults. $₹$ Am Coll Cardiol 1984;4:749-55.

8 Till JA, Baxendall M, Benetar A. Acceleration of the ventricular response to atrial flutter by amiodarone in an infant with Walff-Parkinson-White to atrial flutter by amiodarone in an in

9 ABPI Data Sheet Compendium 1991-92. London: Datapharm Publications, 1991;1347-50.

10 Till J, Herxheimer A. Death of a child with supraventricular tachycardia Lancet 1992;339:1597-8.

11 Perry JC, McQuinn RL, Smith RT, Gothing C, Fredell P, Garson A Flecainide acetate for resistant arrhythmias in the young: efficacy and pharmacokinetics. F Am Coll Cardiol 1989;14:185-91.

12 Ziegler V, Gillette PC, Ross BA, Ewing L. Flecainide for supraventricular and ventricular arrhythmias in children and young adults. Am $\mathcal{f}$ Cardiol 1988;62:818-20.

13 Roden DM, Woosley RL. Flecainide. N Engl f Med 1986;315:36-41.

14 Morganroth J, Horowitz LN. Flecainide: its proarrhythmic and expected changes on the surface electrocardiogram. Am f Cardiol 1984;53:89-94

15 Fish FA, Gillette PC, Benson DW for the pediatric electrophysiology group. Proarrhythmia, cardiac arrest and death in young patients receiving encainide and flecainide. $\mathcal{f} \mathrm{Am}$ Coll Cardiol 1991;18:356-65.

16 Perry JC, Garson A. Flecainide acetate for treatment of tachyarrhythmias in children: review of world literature on efficacy, safety and dosing. $A m$ Heart $71992 ; 124: 1614-21$.

17 Epstein AE. Flecainide for pediatric arrhythmias: do children behave like little adults? $¥ \mathrm{Am}$ Coll Cardiol 1989;14:192-3.

18 Cardiac Arrhythmia Suppression Trial (CAST) Investigators. Preliminary report: effect of encainide and flecainide on mortality in a randomized trial of arrhythmia suppression after myocardial infarction. $N$ Engl $f$ Med 1989;321:406-12.

19 Ruskin JN. The Cardiac Arrhythmia Suppression Trial (CAST). $N$ Engl Med 1989;321:386-8.

20 Hughes MM, Trohman RG, Simmons TW, Castle LW, Wilkoff BL Morant VA, Maloney JD. Flecainide therapy in patients treated for supraventricular tachycardia with near normal left ventricular function. Am Heart F 1992;123:408-12.

21 Perry JC, Garson A. Encainide and flecainide in children: separating the wheat from the chaff. $\mathcal{A}$ Am Coll Cardiol 1991;18:366-7.

22 Reimer A, Paul T, Kallfelz H-C. Efficacy and safety of intravenous and oral propafenone in pediatric cardiac dysrhythmias. Am 7 Cardiol 1991 68:741-4.

23 Maragnes P, Tipple M, Fournier A. Effectiveness of oral sotalol for treatment of pediatric arrhythmias. Am $\mathcal{F}$ Cardiol 1992;69:751-4

24 Committee on Safety of Medicines, personal communication.

25 Neonatal arrhythmias. In: Fleming PJ, Speidel BD, Marlow N, Dunn PM, eds, A neonatal vade mecum. 2nd ed. London: Lloyd Luke, 1991 129-30.

26 Silove E. Congenital heart lesions and cardiac emergencies. In: Insley J. ed, A paediatric vade mecum 11 th ed. London: Lloyd Luke, 1986; 213-16.

27 Supraventricular arrhythmias. British National Formulary, No 24 London: British Medical Association and Royal Pharmaceutical Society of Great Britain, 1992;70.

28 ABPI Data Sheet Compendium 1991-92. London: Datapharm Publications 1991;703-06.

29 Radford D. Side effects of verapamil in infants. Arch Dis Child 1983, 58:465-66.

30 Epstein ML, Kiel EA, Victoria BE. Cardiac decompensation following verapamil therapy in infants with supraventricular tachycardia. Pediatric 1985;75:737-40.

31 Kirk CR, Gibbs JL, Thomas R, Radley Smith R, Qureshi SA Cardiovascular collapse after verapamil in supraventricular tachycardia. Arch Dis Child 1987;62:1265-82. 